\title{
Sensitive Single Step Fluorimetric Method for Monitoring Solid-Phase Reactions on Polystyrene Resin-Bound Chloride Groups
}

\author{
Georgina E. Pina-Luis, ${ }^{*, a}$ Marco A. Zazueta Gómez, ${ }^{a}$ Ignacio A. Rivero Espejel ${ }^{a}$ and \\ Marta E. Díaz-García ${ }^{b}$ \\ ${ }^{a}$ Centro de Graduados e Investigación, Instituto Tecnológico de Tijuana, P.O. 1166, \\ 22000 Tijuana-B.C., México \\ ${ }^{b}$ Departamento de Química Física y Analítica, Facultad de Química, Universidad de Oviedo, \\ Av. Julián Clavería 8, 33006 Oviedo, España
}

\begin{abstract}
Espectroscopia de fluorescência tem sido usada para monitorar a conversão química de resinas ligadas a grupos cloreto. Os perfis tempo-concentração de diferentes reações envolvendo a incorporação de derivados de hidroxifeniletanona (HPE) à resina Merrifield e 2-aminobencilalcool (ABA) à resina clorosulfonada são mostrados. A avaliação do progresso da reação foi feita usando-se um marcador fluorescente imobilizado (dansil hidrazina) e por medidas diretas de fluorescência da espécie formada em cada etapa das reações nos grãos da resina. Não foram observadas diferenças significativas entre estes dois métodos. Os resultados mostraram que medidas diretas na fase sólida sem o uso de marcadores fluorescentes representam uma análise simples, rápida, não destrutiva e de baixo custo para o monitoramento do progresso de reações em resinas cloradas, a qual permite não somente o estudo da cinética de reação, mas também proporciona uma ferramenta valiosa para a quantificação analítica de resina ligada a cloreto, sem nenhuma preparação da amostra, exceto a transferência do grão da resina de cada estágio reacional, do frasco reacional para a célula de fluxo, para a medida de fluorescência.
\end{abstract}

Fluorescence spectroscopy has been used to monitor the chemical conversion of resin-bound chloride groups. The time-concentration profiles of different reactions involving the incorporation of hydroxyphenylethanone (HPE) derivatives to Merrifield resin and 2-aminobencylalcohol (ABA) to a chlorosulphonate resin are shown. The evaluation of the reaction progress was made using an immobilized fluorescent tracer (dansyl hydrazine) and by direct fluorescence measurements of the species formed on each step of the reactions on resin beads. Significant differences between these two methods were not observed. The results demonstrate that direct measurements on solid phase without using fluorescent markers represent a single step, rapid, non destructive and low cost analysis by monitoring reaction progress on chlorinated resins, which allows not only the study of reaction kinetics but also provides a valuable tool for the analytical quantification of chloride resin bound, without any sample preparation, except the transfer of resin bead of each reaction stage from the reaction vessel to the flow cell for the fluorescent measurement.

Keywords: monitoring solid phase reaction, fluorescence, kinetics

\section{Introduction}

Solid phase organic synthesis (SPOS) continues to play an important role in combinatorial chemistry, not only in the preparation of new drugs but in the development of materials with molecular recognition properties. ${ }^{1-7}$ In spite of its extensive use, a critical step in this field is the lack of analytical techniques for monitoring the reaction progress.

*e-mail: gpinaluis@tectijuana.mx,gpinaluis@yahoo.com
Monitoring the course of the reactions on solid phase requires, in many cases, the cleavage of intermediates and products from the support and to use classical techniques for characterization and quantification. However, such approaches present several drawbacks since not all the intermediates are stable to cleavage conditions and low-load resins may not provide enough product for isolation and characterization. In addition the process may involve an unacceptable time delay in achieving the information. For this reason, a great deal of effort has been dedicated over 
the years to find quick and reliable ways for monitoring solid phase reactions.

Classical techniques for following the course of reactions, such as TLC are clearly not applicable in the solid phase mode, while techniques for direct monitoring such as, elemental analysis ${ }^{8,9}$ and other methods as FT-IR, ${ }^{10,12}$ FT-Raman, ${ }^{13} \mathrm{NMR},{ }^{14-17} \mathrm{MS},{ }^{18} \mathrm{X}$-ray photoelectron (XP) spectroscopy, ${ }^{19}$ and electrochemical impedance (ESI), ${ }^{20}$ may result expensive and destructive analysis, or/and need time consuming sample preparation, e.g. for compression molding of $\mathrm{KBr}$ pellets and for high drying of samples. ATR-FTIR (attenuated total reflection Fourier transform infrared) spectroscopy, ${ }^{21}$ allows the direct characterization of solid support, but requires the corresponding equipment complement that is not always available. ESI-MS (electrospray ionization mass spectrometry) offers high sensitivity for analyzing compound released from a resin bead. However, because of the structural diversity of organic compound libraries, many compounds do not have the appropriate ionization properties to be analyzed by ESI-MS. An analytical construct, which contains an amine that enhances electrospray ionization properties and an isotope label, was developed. ${ }^{22}$

In the last years several researchers have rediscovered simple colorimetric tests, ${ }^{23-28}$ that allow the evaluation of the presence of functional group on a variety of solid supports. Although these colorimetric methods are simple and low cost, they are generally indicative and should be used exclusively to monitor the progress of reaction. In addition they require the destruction of a small sample of resin for each assay and extensive time.

So, despite of the efforts made in the development of new methods for monitoring the reaction progress on solid phase, many of the reported procedures involve several stages in their implementation, or/and may result expensive and destructive analysis, or/and may consume a long time of sample preparation. Then, the development of methods that can be carried out in a one step is a true challenge.

Fluorimetric analysis have won great popularity in the last years since they are simple, sensitive and non destructive analysis. ${ }^{29-32}$ As part of interest of our group of solid phase organic synthesis (SPOS), in the development of new solid-phase synthetic methods, we are looking for an easy analytical method for monitoring the reaction progress, that not only attends the study of kinetic reaction, but also allows quantifying the resin-loading. In a previous work, ${ }^{32}$ we have reported the use of a fluorescent tracer (dansyl chloride) as a useful tool for the determination of resinbound hydroxyl groups, for the study reaction kinetics and for monitoring the progress of reactions. In this paper the progress of chlorinated resin conversion in two reactions: (i) the attachment of hydroxyphenylethanone (HPE) on Merrifield resin to obtain methoxyphenylethanone (MPE) resin (Scheme 1), and (ii) the reaction of chlorosulfonate resin with 2-aminobencyl alcohol (ABA) to obtain $N$-(2(hydroxymethyl)phenyl)sulfonamide resin, followed by conversion to the chlorinated resin (Scheme 2) is showed. Our new approach demonstrated that direct measurements on solid phase without using fluorescent markers give good results and represent a single step, simple, rapid, non destructive and low cost analysis by monitoring reaction progress on chlorinated resins and for the study reaction kinetics and analytical quantification of chloride resin bound, without any sample preparation, except the transfer of resin bead in each reaction stage from the reaction vessel to the flow cell for the fluorescent measurement.

\section{Results and Discussion}

\section{Preparation of methoxyphenylethanone-resin and methoxyphenylethylidene-dansyl-hydrazine resin}

PS-chlorometyl resin, known as Merrifield resin, is a useful starting material extensively used in solid phase synthesis. ${ }^{33,34}$ Evaluation of the reaction conversion degree through the chloride group substitution is carried out generally by Volhard titration ${ }^{35}$ after treatment with an amine, which is a long and tedious method. The feasibility of using fluorescence spectroscopy to monitor the reaction of hydroxyphenylethanone (HPE) with Merrifield resin in real-time has been examined. The general solid phase route, which is shown in Scheme 1, begins with the attachment of HPE derivatives 2 (a-c) to Merrifield resin 1, through a nucleophilic displacement of the chloride group catalyzed by $\mathrm{K}_{2} \mathrm{CO}_{3}$, using dimethylformamide as solvent to give the methoxyphenylethanone (MPE) resins 3 (a-c). The resins were then coupled to the high quantum yield fluorescent molecule dansyl hydrazine $\mathbf{4}$, through a condensation reaction of the amine group to the carbonyl group, catalyzed by acid using dimethylformamide as solvent, to obtain methoxyphenylethylidene-dansyl-hydrazine (MPED) resins 5 (a-c), according to the route outlined in Scheme I. The resins were rinsed repeatedly with dichloromethane in order to remove all unreacted dansyl. After a new thorough rinsing with methanol, the resins were vacuum-dried and stored protected from room light. The different reaction steps were monitored by IR and fluorescence spectroscopy. The immobilized MPE 3 (a-c) were cleaved from the polymer by treatment with a solution of trifluoroacetic acid-dichloromethane (1:10) for 30 min under ultrasonic conditions. The resins were filtered and $1 \mu \mathrm{L}$ of the washing solution was directly injected on an ESI-MS for 
analysis. The corresponding cuasi molecular ions $[\mathrm{M}+\mathrm{H}]^{+}$ were obtained confirming the presence of the MPE on the polymer support.

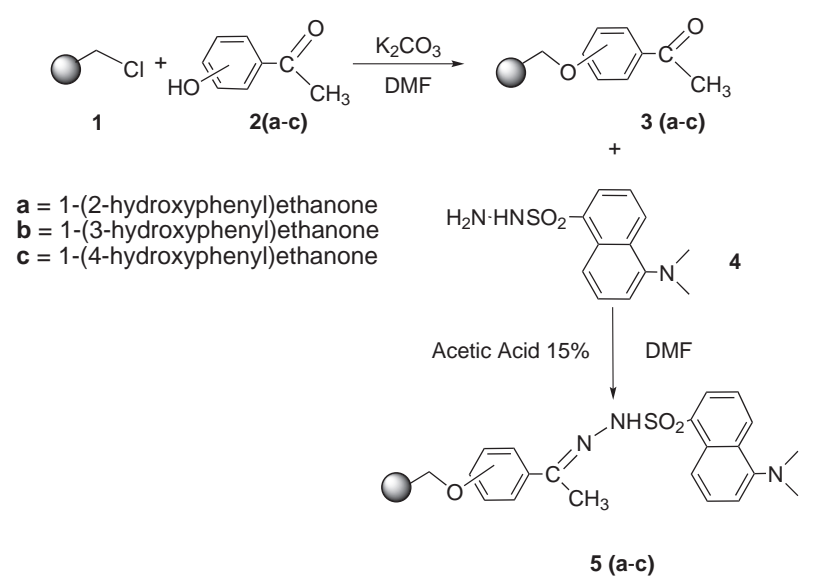

Scheme 1. Preparation of modified resins $\mathbf{3}(\mathbf{a}-\mathbf{c})$ and $\mathbf{5}(\mathbf{a}-\mathbf{c})$.

\section{Fluorimetric characterization}

The fluorescence spectral behavior of the starting material, intermediates and final products were studied in order to evaluate the structural changes at different stages. Resins were transferred to a conventional flow-through fluorescence cell, and spectra were obtained directly from the dry resin beads. Fluorescence spectra of Merrifield resin 1, 1-(3-methoxyphenyl)ethanone resin $\mathbf{3 b}$ and 1-(3-methoxyphenyl)ethylidene-dansyl-hydrazine resin $5 \mathbf{b}$ are shown in Figure 1. There are marked differences in the spectrum between the unmodified resin and the final products, indicating an effective incorporation of MPE into the resins. The fluorescence spectra of Merrifield resin $\mathbf{1}\left(\lambda_{\text {exc }}=374 \mathrm{~nm}\right.$, $\lambda_{\text {em }}=454 \mathrm{~nm}$ ) correspond to $\pi^{*}-\pi$ electronic transitions of the polymeric matrix based on polystyrene cross linked with divinyl benzene. The fluorescence spectra of resin 3b $\left(\lambda_{\text {exc }}=386 \mathrm{~nm}, \lambda_{\text {em }}=460 \mathrm{~nm}\right)$ are shifted from those of Merrifield resin, due to $\pi^{*}$-n transition of low intensity which appears at longer wavelength corresponding to the carbonyl groups. The electronic delocalization of the $\pi$ system is not sufficient to induce fluorescence due to $\pi^{*}-\pi$ transition, thus a decrease in fluorescence intensity is observed. The incorporation of dansyl probes gives rise to an increase in the fluorescence intensity, (in agreement with their high quantum yield), a red shift fluorescence spectra $\left(\lambda_{\mathrm{exc}}=396 \mathrm{~nm}\right.$, $\lambda_{\text {em }}=497 \mathrm{~nm}$ ) and shorter Stoke's shift in comparison with spectra of the dansyl label in solution $\left(\lambda_{\mathrm{exc}}=340 \mathrm{~nm}\right.$, $\lambda_{\mathrm{em}}=525 \mathrm{~nm}$, in methanol). The latter is a consequence of the influence of the local molecular viscosity of polymer, preventing a sufficiently fast relaxation to a state of minimum energy, as compared with a homogenous solution.

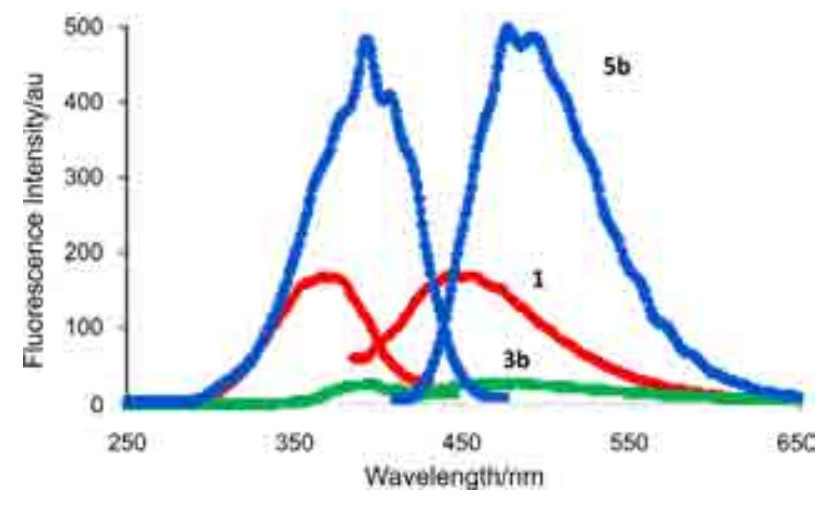

Figure 1. Fluorescence spectra of Merrifield resin $1\left(\lambda_{\mathrm{exc}}=374 \mathrm{~nm}\right.$, $\left.\lambda_{\mathrm{em}}=454 \mathrm{~nm}\right), 1$-(3-methoxyphenyl) ethanone resin $\mathbf{3 b}\left(\lambda_{\mathrm{exc}}=386 \mathrm{~nm}\right.$, $\left.\lambda_{\mathrm{em}}=460 \mathrm{~nm}\right)$ and 1-(3-methoxyphenyl)ethylidene-dansyl-hydrazine resin $\mathbf{5 b}\left(\lambda_{\mathrm{exc}}=396 \mathrm{~nm}, \lambda_{\mathrm{em}}=497 \mathrm{~nm}\right)$.

A very small particle size of the resin can lead to a high compacting degree. In this condition a reduction of fluorescence intensity caused by inner filter effect could be appreciated. We work with 75-150 $\mu$ m (100-200 mesh) resins, which under the reaction conditions did not show a significant change of particle size. We verified this by measuring the fluorescence of resins beads before and after of a "blank" reaction, which includes all the reagents except the modifier reagent of the resin. Fluorescence intensity variations of the resin were not observed, indicating that inner filter effects and undesired reactions have not taken place.

\section{Kinetics of the reaction on solid-phase}

The evaluation of reaction progress was made measuring the fluorescence on resin beads before and after the fluorescent tracer molecule immobilization. The reaction kinetic of the 3-MPE resin $\mathbf{3 b}$ formation was followed first by incorporation of the dansyl hydrazine fluorophore probe (dansyl:resin, 1:1). The excitation and fluorescence spectra of 3-MPED modified resin $\mathbf{5 b}$ at different reaction times are shown in Figure 2A. As observed, fluorescence intensity at maximum emission wavelength increases as reaction time increases up to $6 \mathrm{~h}$, indicating the incorporation of the fluorescent probe. Reaction kinetics was also followed by fluorescence spectroscopy without any manipulation of 3-MPE resin $\mathbf{3 b}$, except to transfer it to a conventional flow-through fluorescence cell. As illustrated in Figure 2B, under the experimental conditions, the fluorescence spectra of 3-MPE resin $\mathbf{3 b}$ at different reaction times show a decrease of fluorescence intensity as reaction time increases, indicating the incorporation of MPE on the resin (carbonyl groups). Above $6 \mathrm{~h}$ fluorescence 
intensity remains constant. It shows that the variation of fluorescence intensity with reaction time has a similar behavior by both methods and suggests the possibility of evaluating reaction kinetics without any transformation of the resin.
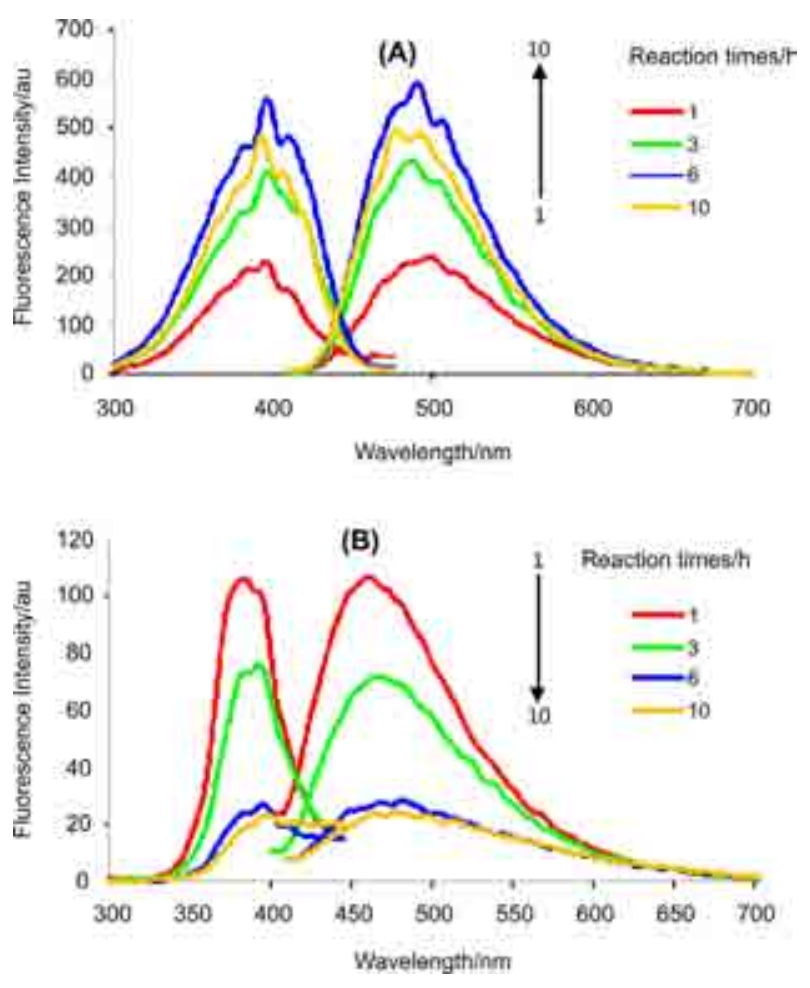

Figure 2. (A) Fluorescence spectra of 1-(3-methoxyphenyl)ethylidenedansyl-hydrazine resin $\mathbf{5 b}$ (dansyl:resin $=1: 1)$ at different reaction times. $\lambda_{\text {exc }}=396 \mathrm{~nm}$. (B) Fluorescence spectra of 1-(3-methoxyphenyl) ethanone resin $\mathbf{3 b}$ at different reaction times. $\lambda_{\mathrm{exc}}=386 \mathrm{~nm}$.

The results obtained in the evaluation of reaction progress by direct measurements of fluorescence intensity, were validated by the volumetric Volhard method. In Figure 3 reaction kinetics of the HPE incorporation on Merrifield resin using: Direct measurements of fluorescence intensity on resin beads and Volhard method for the evaluation of chloride substitution (\%) is presented. As observed, evaluation of the reaction kinetics by fluorescence spectroscopy, demonstrated a greater sensitivity, since this method allows establishing the difference between the time-concentration profile of $\mathbf{3 b}$ and $\mathbf{3 c}$ formation, while the Volhard method gives similar results.

Kinetics of the reaction of MPE resin formation on solid phase showed that the time course of the reaction fitted a pseudo-first-order reaction rate equation. The data were analyzed according to rationalizations reported in a previous work, ${ }^{32}$ by fitting the equation:

$[\mathrm{R}-\mathrm{MPE}]_{\mathrm{t}}=[\mathrm{R}-\mathrm{Cl}]_{\mathrm{o}}\left(1-\mathrm{e}^{-\mathrm{kt}}\right)$ where $[\mathrm{R}-\mathrm{MPE}]_{\mathrm{t}}$ is the concentration of methoxyphenylethanone inmobilized at any time and $[\mathrm{R}-\mathrm{Cl}]_{\mathrm{o}}$ is the initial concentration of reactive sites.

According to the reaction:

$$
\begin{array}{r}
\mathrm{R}-\mathrm{Cl}+\mathrm{HPE} \rightarrow \mathrm{R}-\mathrm{MPE} \\
(\mathrm{HPE} \text { is in large excess) }
\end{array}
$$

it was possible to quantify the rate constant $\mathrm{k}$, by monitoring the fluorescence of the system, taking into account that at any time, the observed fluorescence intensity of a given sample was equal to the sum of fluorescence intensities of the species present. Merrifield resin and MPE resin were the only fluorescent since free HPE had been removed by washing.
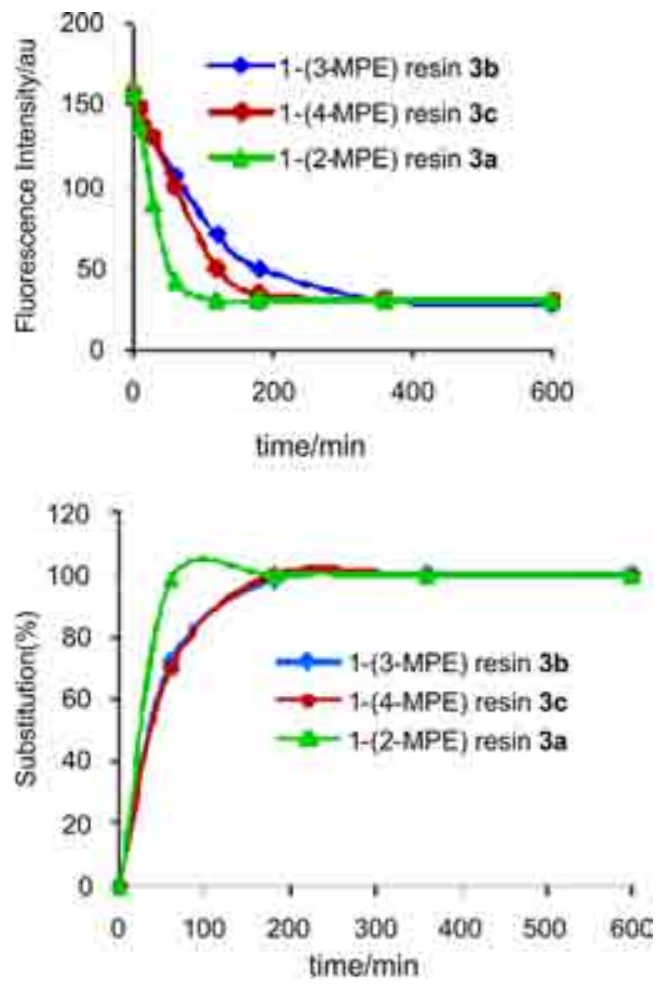

Figure 3. Reaction kinetics of the MPE resin formation using: A) Direct measurements of fluorescence intensity on resin beads. Excitation is at $386 \mathrm{~nm}$, and emission is monitored at $460 \mathrm{~nm}$. B) Volhard method for the evaluation of chloride substitution (\%).

Then, under the experimental conditions:

$\mathrm{I}_{\mathrm{o}}=\mathrm{a}[\mathrm{R}-\mathrm{Cl}]$ at $\mathrm{t}=0$

$\mathrm{I}_{\mathrm{t}}=\mathrm{b}[\mathrm{R}-\mathrm{MPE}]$ at any time

where $\mathrm{a}$ and $\mathrm{b}$ are functions of the concentration of $\mathrm{R}-\mathrm{Cl}$ and R-MPE, respectively.

Equations 1,2 and 3 may be combined into the form:

$\log \left(\mathrm{I}_{\mathrm{t}} / \mathrm{I}_{0}\right)=\log \mathrm{b} / \mathrm{a}-\mathrm{kt} / 2.303$ 
Plots of $\log \left(\mathrm{I}_{\mathrm{t}} / \mathrm{I}_{0}\right)$ versus $\mathrm{t}$ resulted in straight lines from which the $\mathrm{k}$ values were obtained for the derivative under study. Kinetic data are collected in Table 1.

Table 1. Kinetics parameters resulting of HPE incorporation on Merrified resin

\begin{tabular}{lc}
\hline Methoxyphenylethanone derivative & $\begin{array}{c}\text { Fluorescence method } \\
\mathrm{K} \times 10^{-5} / \mathrm{s}^{-1}\end{array}$ \\
\hline 2-methoxyphenylethanone & 51.84 \\
4-methoxyphenylethanone & 11.52 \\
3-methoxyphenylethanone & 6.9 \\
\hline
\end{tabular}

The rate constant for 2-MPE resin 3a formation was 4.5 times higher than for 4-MPE resin $3 c$ and 7.5 times higher than for 3-MPE resin $\mathbf{3 b}$. The significant increase in reactivity of 2-HPE derivative toward nucleophilic displacement of the chloride group may be attributed to the position of hydroxyl group in the aromatic ring (orto effect). In addition, the higher rate constant for orto- and para-MPE resin formation is favored by resonance effect.

The kinetic parameters obtained by both methods (Volhard and proposed method) were compared statistically for a significance level of $95 \%$. Significant differences were not observed.

\section{Determination of the resin loading}

Merrifield resin was loaded with varying equivalents of 3-HPE and the emission spectra were obtained at $\lambda_{\text {exc }}=380 \mathrm{~nm}$. The spectral maxima were independent of the probe concentrations, and peak intensity decreased continuously with the concentration of the 3-HPE. Figure 4 shows the variation of fluorescence intensity measured at a wavelength of maxima emission $(460 \mathrm{~nm})$ with the HPE/resin $\left(\mathrm{mmol} \mathrm{g}^{-1}\right)$ ratio. This ratio is a useful tool for estimate the HPE fractional occupancy in the resin. From the data in Figure 4, it can be observed that fluorescence intensity exhibits a linear dependence on the amount of the HPE attached to the resins. The fluorescence intensity will be directly proportional to the extent of reaction occurred. At a given HPE/resin ratio, fluorescence intensities reached a minimum limiting value, indicating saturation at reactive sites. By extrapolation of the linear segments of each curve, the intersection point would be a measure of the corresponding resin-bound chloride groups. Thus, the value of $\mathrm{mmol} \mathrm{g}^{-1}$ resin for Merrifield PS resin was found (1.43) and is in good agreement (accuracy within $1-5 \%$ ) with the loading values reported by the manufacturer $\left(1.41 \mathrm{mmol} \mathrm{g}^{-1}\right)$. These results are consistent with the fact that all binding sites are accessible to 3-HPE.

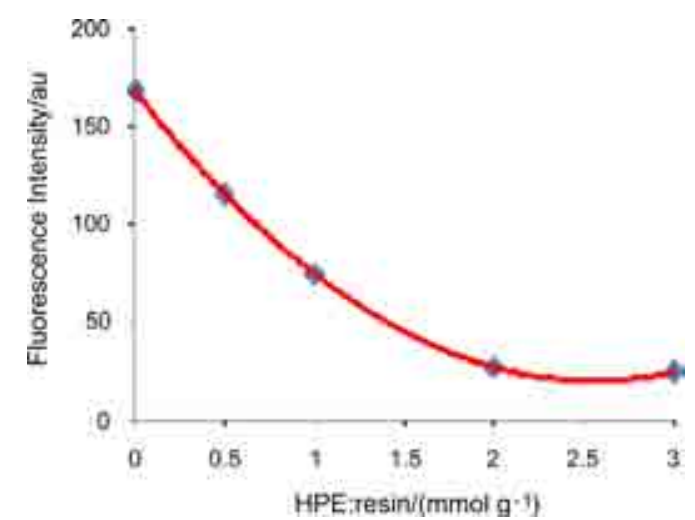

Figure 4. Dependence of the fluorescence intensity with 3-hydroxyphenylethanone (HPE)/resin ( $\mathrm{mmol} \mathrm{g}^{-1}$ ) ratio. Emission is monitored at $460 \mathrm{~nm}$.

\section{Preparation of $\mathrm{N}-(2-($ hydroxymethyl)phenyl)sulfonamide resin}

$\mathrm{PS}-\mathrm{TsCl}$ is a chlorosulfonate polystyrene resin, which is a resin-bound equivalent to tosyl chloride. This resin can readily react with nucleophiles to give a variety of sulfonyl functional polymers, which can be used as polymeric supports, reagents and catalysts in organic synthesis. ${ }^{36}$ The loading of primary alcohols to PS-TsCl resin, may be monitored using a laborious bead staining test. To check for residual sulfonyl chloride groups on the resin, a few beads may be sampled, washed and treated appropriately to determine if the reaction is complete. In this work a new fluorimetric method is used to monitor the reaction of $\mathrm{PS}-\mathrm{TsCl}$ with 2-aminobencyl alcohol (ABA) and the posterior conversion to the chlorinated resin. The route for the synthesis, which is shown in Scheme 2, began by attaching 2-ABA 7 to chlorosulphonate resin $\mathbf{6}$, through a nucleophilic displacement of the chloride group using dichloromethane as solvent to give the $\mathrm{N}$-(2-(hydroxymethyl)phenyl)sulfonamide resin 8 . Conversion of the hydroxyl resin to the chlorinated one was carried out with triphosgene (BTC) and triphenyl phosphine in dichloromethane as described in experimental section to produce the $\mathrm{N}$-(2-(chloromethyl)phenyl)sulfonamide resin 9.

\section{Fluorescence characterization}

The fluorescence spectral behavior of starting material, intermediates and final products were studied in order to evaluate the structural changes at different steps. Resins were transferred to a conventional flow-through fluorescence cell, and spectra were obtained directly from the dry resin beads. The fluorescence spectra of chlorosulphonate resin $\mathbf{6}, \mathrm{N}$-(2-(hydroxymethyl)phenyl) 


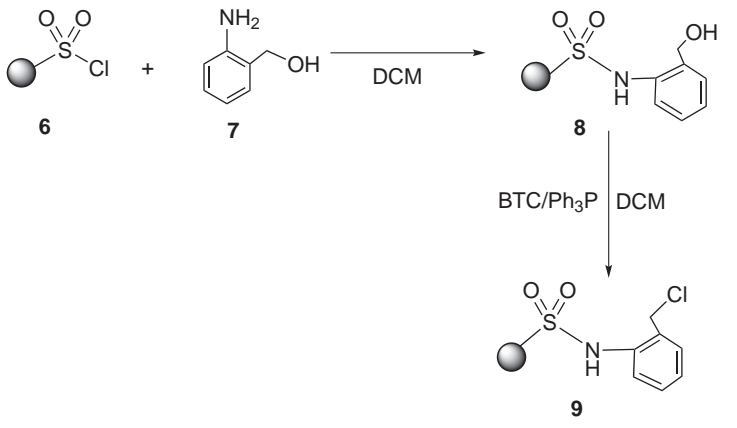

Scheme 2. Preparation of modified resins 8 and 9.

sulfonamide resin 8 and $N$-(2-(chloromethyl)phenyl) sulfonamide resin 9 are shown in Figure 5. There are marked differences in the spectrum from the "blank" resin (unmodified) to the final products, indicating an effective incorporation of the $\mathrm{ABA}$ into the resins. The fluorescence spectra of resin $8\left(\lambda_{\text {exc }}=490 \mathrm{~nm}, \lambda_{\text {em }}=547 \mathrm{~nm}\right)$ are shifted to that of chlorosulphonate resin $6\left(\lambda_{\text {exc }}=460 \mathrm{~nm}\right.$, $\left.\lambda_{\mathrm{em}}=528 \mathrm{~nm}\right)$ and an increase of the fluorescence intensity with a greater fluorescence efficiency of the corresponding unmodified resin is shown.

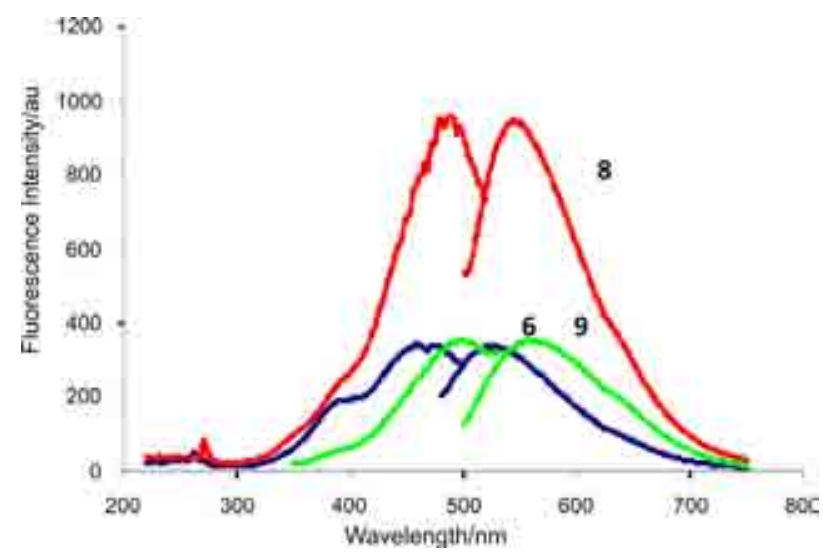

Figure 5. Fluorescence spectra of chlorosulphonate resin $6\left(\lambda_{\text {exc }}=460 \mathrm{~nm}\right.$, $\left.\lambda_{\mathrm{em}}=528 \mathrm{~nm}\right), N$-(2-(hydroxymethyl) phenyl) sulfonamide resin 8 $\left(\lambda_{\text {exc }}=490 \mathrm{~nm}, \lambda_{\text {em }}=547 \mathrm{~nm}\right)$ and $N$-(2-(chloromethyl)phenyl)sulfonamide $\operatorname{resin} 9\left(\lambda_{\mathrm{exc}}=506 \mathrm{~nm}, \lambda_{\mathrm{em}}=555 \mathrm{~nm}\right)$.

This behavior is due to the substitution of chlorine in the resin by an aromatic ring, which increases the conjugation extent of the $\pi$ electronic system in the resin. The subsequent chlorination reaction leads to a decrease in the fluorescence intensity due to the effect of chlorine, which acts as a heavy atom, favoring the intersystem crossing and deactivating the fluorescence.

\section{Determination of the resin loading}

Resin 6 was loaded with varying equivalents of the aminobenzyl alcohol (ABA), and the excitation and emission spectra were recorded. The spectral maxima were independent of the probe concentrations, and peak intensity increased continuously with the concentration of ABA. In Figure 6 the variation of fluorescence intensity measured at maxima emission wavelength $(547 \mathrm{~nm})$ with the $\mathrm{ABA} /$ resin $\left(\mathrm{mmol} \mathrm{g}^{-1}\right)$ ratio is presented. It can be observed that fluorescence intensity exhibits a linear dependence on the amount of alcohol attached to the resins, even at high loadings of the ABA, and no self-quenching or reabsorption effects were observed. Since only the attached ABA is fluorescent (beads were subjected to repeated washings), the fluorescence intensity will be directly proportional to the extent of reaction occurred. At a given ABA/resin mmol g ${ }^{-1}$ ratio, fluorescence intensities reached a limiting value, indicating saturation at reactive sites. By extrapolation of the linear segments of each curve, the intersection point would be a measure of the corresponding resin-bound hydroxyl groups. Thus, the value of $\mathrm{mmol} \mathrm{g}^{-1}$ resin for chlorosulphonate PS resin was found $\left(1.61 \mathrm{mmol} \mathrm{g}^{-1}\right)$ and is in good agreement (accuracy within 1-5\%) with the loading values reported by the manufacturer $\left(1.64 \mathrm{mmol} \mathrm{g}^{-1}\right)$. These results are consistent with the fact that all binding sites are accessible to aminobenzyl alcohol.

Additionally, the fluorescence spectra of the ABA binding to resin at different reaction times were analyzed. According to fluorescence monitoring, reaction is completed at $20 \mathrm{~min}$. Analysis by Volhard method, showed $100 \%$ of conversion at $20 \mathrm{~min}$.

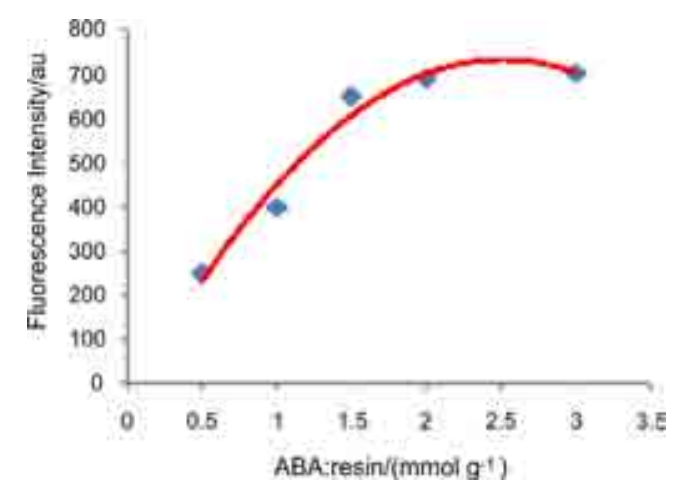

Figure 6. Dependence of the fluorescence intensity with $\mathrm{ABA} / \mathrm{resin}$ $\left(\mathrm{mmol} \mathrm{g}^{-1}\right)$ ratio. Emission is monitored at $547 \mathrm{~nm}$.

\section{Kinetics of a chlorination reaction on solid-phase}

The chlorination reaction was carried out as described in the experimental section. The reaction was stopped at different times as specified, and the fluorescence spectra of the chlorinated resins were recorded. It was observed that the fluorescence intensity of the unlabeled ("blank" resin) decreases while the chlorination reaction is taking place. However, the native fluorescence intensity decreases as 
the $\mathrm{OH}$ groups were substituted by chlorine. As illustrated in Figure 7A, under the experimental conditions, the fluorescence spectra of $N$-(2-(hydroxymethyl)phenyl) sulfonamide resin $\mathbf{8}$ show a decrease of the fluorescence intensity as chlorination reaction time increases. Above $50 \mathrm{~min}$ the fluorescence intensity remains constant. In Figure $7 \mathrm{~B}$ the dependence of fluorescence intensity at maximum emission wavelength with reaction time is presented. These results were validated using Volhard method.
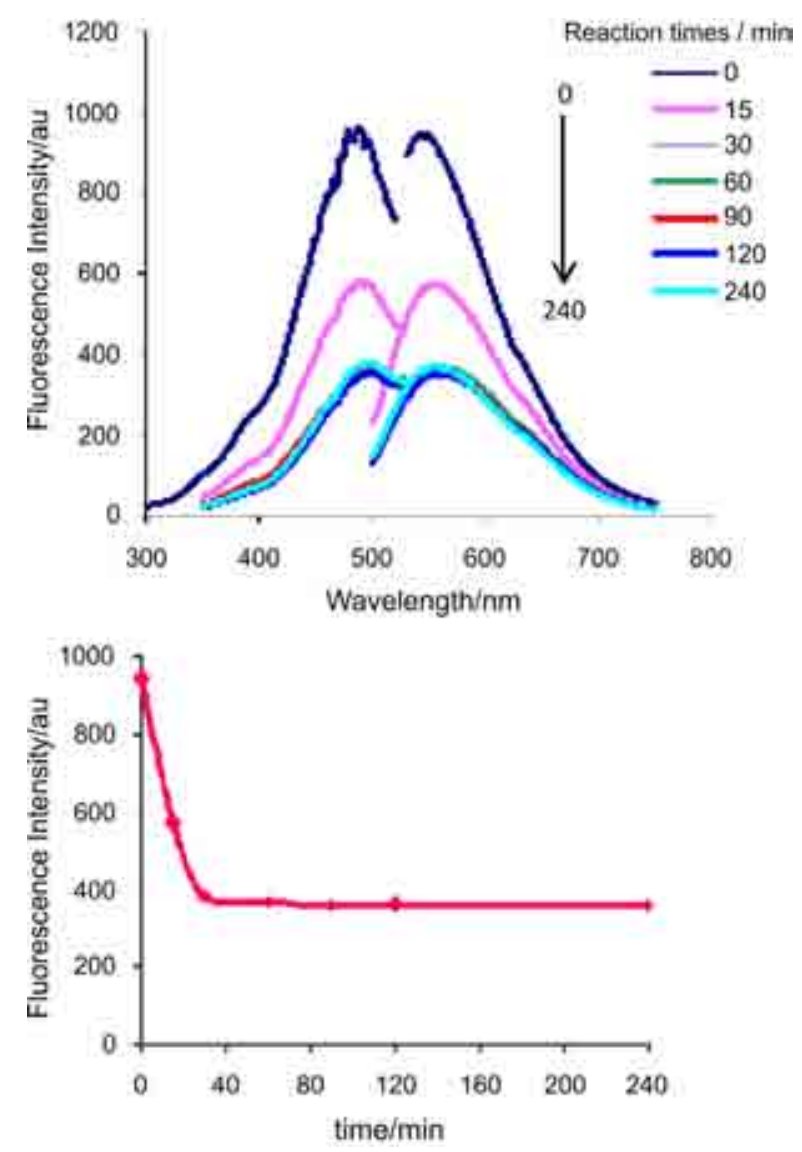

Figure 7. (A) Fluorescence spectra of $N$-(2-(hydroxymethyl)phenyl) sulfonamide chlorination at different reaction times. $\lambda_{\text {exc }}=490 \mathrm{~nm}$, $\lambda_{\text {em }}=547 \mathrm{~nm}$. (B) Fluorescence intensity $v s$. reaction time for the conversion of hydroxyl resins to chlorinated ones. Emission is monitored at $547 \mathrm{~nm}$.

The kinetics data analysis indicated a pseudo first-order rate constant of $4.98 \times 10^{-4} \mathrm{~s}^{-1}$ for the $N$-(2-(hydroxymethyl) phenyl)sulfonamide chlorination reaction.

\section{Conclusions}

In conclusion, a single step, easy, fast and highly sensitive fluorescent method was successfully used to evaluate the different reaction steps and to determine not only if the reaction has proceeded to completion, but also the kinetics of different reactions by direct measurement of fluorescence on solid phase without using a fluorescent tracer. The proposed method reduces the time and the cost of the analysis, since it eliminates reactions steps and reagents, is not destructive and does not require expensive equipment. The method also proved to be useful in the determination of the loading of Merrifield resin and chlorosulphonate resin. The approach offers a real time insight into chemistry taking place on the resin and can be extended to monitor a variety of reactions on solid supports, and in conjunction with a well-established technique such as flow analysis, basic studies on solidphase become possible.

\section{Experimental}

Merrifield resin $\left(1.41 \mathrm{mmol} \mathrm{g}^{-1} \mathrm{Cl}\right)$ and chlorosulphonate resin $\left(1.64 \mathrm{mmol} \mathrm{g}^{-1} \mathrm{Cl}\right)$ used in this work were purchased from Argonaut Technologies Inc. (USA). All other reagents, unless otherwise specified, were purchased from Aldrich Chem. Co. (St. Louis, USA). Infrared (IR) spectra were recorded on a Perkin Elmer FT-IR 1600 spectrometer (USA). Mass spectra were obtained on a Hewlett Packard 5989 MS spectrometer (USA) at $70 \mathrm{eV}$ by direct insertion. The Fluorescence spectra were recorded on a spectrofluorometer Shimadzu RF-5301 PC (Kyoto, Japan). Beads were washed free of any starting materials and solvents and were placed into a Hellma model 176.52 flow-through cell (Müllheim, Germany) for fluorimetric analysis.

General method for the synthesis of methoxyphenylethanone on Merrifield resin $\mathbf{3}(\boldsymbol{a}-\boldsymbol{c})$

Merrifield resin (1.0 g, $1.4 \mathrm{mmol})$ was expanded during $15 \mathrm{~min}$ in $10 \mathrm{~mL}$ of DMF. Then, $\mathrm{K}_{2} \mathrm{CO}_{3}(4.83 \mathrm{~g}, 35 \mathrm{mmol})$, hydroxyphenylethanone 2 (a-c) $(0.95 \mathrm{~g}, 7 \mathrm{mmol})$ and $10 \mathrm{~mL}$ of DMF were added. The mixture was heated at $75^{\circ} \mathrm{C}$ under constant stirring during $10 \mathrm{~h}$, after which the resin was filtered and washed with $\mathrm{H}_{2} \mathrm{O}(3 \times 30 \mathrm{~mL}), \mathrm{MeOH}$ $(3 \times 20 \mathrm{~mL})$ and $\mathrm{CH}_{2} \mathrm{Cl}_{2}(3 \times 20 \mathrm{~mL})$. Finally, the resin was dried under reduced pressure.

\section{2-Methoxyphenylethanone resin $\mathbf{3 a}$}

Recovery: 90\%. Conversion (Volhard): 100\%. FTIR $(\mathrm{KBr}) v_{\max } / \mathrm{cm}^{-1}$ : $3025(\mathrm{C}-\mathrm{H} \mathrm{Ar}), 1675(\mathrm{C}=\mathrm{O}), 1596(\mathrm{C}=\mathrm{C})$, $1268(\mathrm{C}-\mathrm{O}) . \mathrm{FI}=28 \mathrm{au}, \lambda_{\mathrm{em}}=460 \mathrm{~nm}, \lambda_{\text {exc }}=386 \mathrm{~nm}$. ESI-MS: $[\mathrm{M}+\mathrm{H}]^{+}=133$.

\section{3-Methoxyphenylethanone resin $\mathbf{3} \boldsymbol{b}$}

Recovery 90\%. Conversion (Volhard): 100\%. FTIR $(\mathrm{KBr}) v_{\max } / \mathrm{cm}^{-1}: 3024(\mathrm{C}-\mathrm{H}$ Ar), $1684(\mathrm{C}=\mathrm{O}), 1594(\mathrm{C}=\mathrm{C})$, 
$1268(\mathrm{C}-\mathrm{O}) . \mathrm{FI}=52 \mathrm{au}, \lambda_{\mathrm{em}}=460 \mathrm{~nm}, \lambda_{\mathrm{exc}}=386 \mathrm{~nm}$. ESI-MS : $[\mathrm{M}+\mathrm{H}]^{+}=133$.

\section{4-Methoxyphenylethanone resin $3 c$}

Recovery: $82 \%$. Conversion (Volhard): $100 \%$. FTIR $(\mathrm{KBr}) v_{\max } / \mathrm{cm}^{-1}: 3025(\mathrm{C}-\mathrm{H} \mathrm{Ar}), 1675(\mathrm{C}=\mathrm{O}), 1597(\mathrm{C}=\mathrm{C})$, $1252(\mathrm{C}-\mathrm{O}) . \mathrm{FI}=30 \mathrm{au}, \lambda_{\mathrm{em}}=460 \mathrm{~nm}, \lambda_{\mathrm{exc}}=386 \mathrm{~nm}$. ESI-MS :[M+H $]^{+}=133$.

General method for the synthesis of 1-(methoxyphenyl) ethylidene-dansyl-hydrazine resin $\mathbf{5}(\boldsymbol{a}$-c)

Methoxyphenylethanone resin 3(a-c) (200 mg, $0.28 \mathrm{mmol}$ ) was expanded during $15 \mathrm{~min}$ in $1.25 \mathrm{~mL}$ of DMF. Then a solution of dansyl hydrazine $(33 \mathrm{mg}$, $0.125 \mathrm{mmol}$ ) dissolved in $1 \mathrm{~mL}$ of glacial acetic acid $15 \%$ in DMF was added and the mixture stirred in a sonic bath for $2 \mathrm{~h}$. The resin was filtered and washed with DMF $(2 \times 10 \mathrm{~mL}), \mathrm{MeOH}(3 \times 10 \mathrm{~mL})$ and $\mathrm{CH}_{2} \mathrm{Cl}_{2}(1 \times 10 \mathrm{~mL})$. Finally the resins were dried under reduced pressure. Measurements of fluorescence intensity were obtained directly from the resin beads.

\section{1-(2-Methoxyphenyl)ethylidene-dansyl-hydrazine resin $5 \boldsymbol{a}$}

FTIR (KBr) $v_{\max } / \mathrm{cm}^{-1}: 3446,3019,2920,1654,1605$, $1490,1455,1330,1150 . \mathrm{FI}=530 \mathrm{au}, \lambda_{\mathrm{em}}=497 \mathrm{~nm}$, $\lambda_{\text {exc }}=396 \mathrm{~nm}$.

1-(3-Methoxyphenyl)ethylidene-dansyl-hydrazine resin $\mathbf{5 b}$

FTIR (KBr) $v_{\max } / \mathrm{cm}^{-1}: 3442,3020,2945,1654,1605$, 1490, 1466, 1320, 1130. FI $=612 \mathrm{au}, \lambda_{\mathrm{em}}=497 \mathrm{~nm}$, $\lambda_{\text {exc }}=396 \mathrm{~nm}$.

1-(4-Methoxyphenyl)ethylidene-dansyl-hydrazine resin $5 \boldsymbol{c}$ FTIR (KBr) $v_{\text {max }} / \mathrm{cm}^{-1}: 3450,3024,2960,1654,1605$, $1495,1455,1350,1177$. FI $=515 \mathrm{au}, \lambda_{\mathrm{em}}=497 \mathrm{~nm}$, $\lambda_{\text {exc }}=396 \mathrm{~nm}$.

General method for the synthesis of N-(2-(hydroxymethyl) phenyl)sulfonamide resin 8

Chlorosulfonate polystyrene (PS-Ts-Cl) resin (1.0 g, $1.64 \mathrm{mmol}$ ) was expanded during $10 \mathrm{~min}$ in $2 \mathrm{~mL}$ of $\mathrm{CH}_{2} \mathrm{Cl}_{2}$ with 3 drops of TEA. Then, 2-aminobencyl alcohol (0.605 g, $4.92 \mathrm{mmol})$ in $10 \mathrm{~mL}$ of $\mathrm{CH}_{2} \mathrm{Cl}_{2}$ was added. The mixture was stirred during $2 \mathrm{~h}$ in ultrasonic bath after which the resin was filtered and washed with $\mathrm{CH}_{2} \mathrm{Cl}_{2}(3 \times 20 \mathrm{~mL})$ and $\mathrm{MeOH}(3 \times 20 \mathrm{~mL})$. Finally the resin was dried under reduced pressure. FTIR $(\mathrm{KBr}) v_{\max } / \mathrm{cm}^{-1}: 3373,3045$, $1595,1499,1470,1340,1130$. FI $=743$ au, $\lambda_{\text {exc }}=490 \mathrm{~nm}$, $\lambda_{\mathrm{em}}=547 \mathrm{~nm} .[\mathrm{M}+\mathrm{H}]^{+}=123$. Conversion (Volhard): $100 \%$.
General methodfor the chlorination of N-(2-(hydroxymethyl) phenyl)sulfonamide resin

Conversion of hydroxyl resins to chlorinated ones was carried out according to the chlorination method described elsewhere. ${ }^{34}$ Triphosgene (BTC) (1.46 g) was added with constant stirring to a solution of triphenylphosphine (3.47 g) dissolved in $\mathrm{CH}_{2} \mathrm{Cl}_{2}$ at $0{ }^{\circ} \mathrm{C}(1: 2.7$ stoichiometric molar ratio), then the mixture was stirred for $20 \mathrm{~min}$ at $20{ }^{\circ} \mathrm{C}$, after which the solvent was removed in a vacuum. The crude white solid obtained was dissolved in $20 \mathrm{~mL}$ of $\mathrm{CH}_{2} \mathrm{Cl}_{2}$ to obtain the chlorination reagent solution. The $\mathrm{N}$-(2-(hydroxymethyl)phenyl)sulfonamide resin $(150 \mathrm{mg}$ ), placed in a reactor, was swollen in $\mathrm{CH}_{2} \mathrm{Cl}_{2}(5 \mathrm{~mL})$ and shaken for at least $30 \mathrm{~min}$, then the vessels were drained, and the chlorination reagent solution $(1 \mathrm{~mL}=1$ equiv. chlorination solution) was added to the resins. The reaction was allowed to proceed for $0,10,30,60,90,120$ and 240 min. FTIR (KBr) $v_{\max } / \mathrm{cm}^{-1}: 3040,1593,1489,1465$, 1330, 1140. FI $=360 \mathrm{au}, \lambda_{\text {exc }}=506 \mathrm{~nm}, \lambda_{\text {em }}=555 \mathrm{~nm}$. ESI-MS : $[\mathrm{M}+\mathrm{H}]^{+}=141$.

\section{Acknowledgments}

The authors gratefully acknowledge financial support from the CONACYT (Consejo Nacional de Ciencia y Tecnología, Proyect 67862) and the DGEST (Dirección General de Estudios Superiores Tecnológicos, Proyect 309.06-P). We also acknowledge Dr. Miguel Parra-Hake for valuable comments in the manuscript.

\section{References}

1. Hudson, D.; J. Comb. Chem. 1999, 1, 403.

2. Dolle, R. E.; J. Comb. Chem. 2001, 3, 477.

3. Dolle, R.E.; J. Comb. Chem. 2002, 4, 370.

4. Hermkens, P. H. H.; Ottenheijm, H. C. J.; Rees, D.; Tetrahedron 1996, 52, 4527.

5. Díaz-García, M. E.; Pina-Luis, G.; Rivero, I. A.; TrAC, Trends Anal. Chem. 2006, 25, 112.

6. Rivero, I. A.; González, T.; Pina-Luis, G.; Díaz-García, M. E.; J. Comb. Chem. 2005, 6, 46.

7. Vélez López, E.; Pina Luis, G.; Suárez-Rodríguez, J. L.; DíazGarcía, M. E.; Rivero, I. A.; Sens. Actuators, B 2003, 90, 256.

8. Mazur, S.; Jayalekshmy, P.; J. Am. Chem. Soc. 1979, 101, 677.

9. Yan, B.; Jewell, C. F.; Myers, S. W.; Tetrahedron 1998, 54, 11755.

10. Yan, B.; Gremlich, H. U.; Moss, S.; Coppola, G. M.; Sun,Q.; Liu, L.; J. Comb. Chem. 1999, 1, 46.

11. Yan, B.; Fell, J. B.; Kumaravel, G.; J. Org. Chem. 1996, 61, 7467. 
12. Antonow, D.; Graebin, C. S.; Eifler-Lima, V. L.; J. Braz. Chem. Soc. 2004, 15, 782.

13. Altava, B.; Burguete, M. I.; Garc1a-Verdugo, E.; Luis, S. V.; Vicent, M. J.; Tetrahedron 2001, 57, 8675.

14. Seeberger, P. H.; Beebe, X.; Sukenick, G. D.; Pochapsky, S.; Danishefsky, S. J.; Angew. Chem., Int. Ed. 1997, 366, 491.

15. Jamieson, C.; Congreve, M. S.; Hewitt, P. R.; Scicinski, J. J.; Ley, S. V.; J. Comb. Chem. 2001, 3, 397.

16. Fernandez-Forner, D.; Huerta, J. M.; Ferrer, M.; Casals, G.; Ryder, H.; Giralt, E.; Albericio, F.; Tetrahedron Lett. 2002, 43, 3543.

17. Le Roy, I.; Mouysset, D.; Mignani, S.; Vuilhorgne, M.; Stella, L.; Tetrahedron 2003, 59, 3719.

18. Rousselot-Pailley, P.; Ede, N. J.; Lippens, G.; J. Comb. Chem. 2001, 3, 559.

19. Yoo, S.-e.; Gong, Y.-D.; Seo, J.-s.; Sung, M. M.; Lee, S. S.; Kim, Y.; J. Comb. Chem. 1999, 1, 177.

20. Hutton, R. S.; Adams, J.P.; Trivedi, H. S.; Analyst 2003, 128, 103.

21. Hwang J. Y.; Lee, D-H.; Yoo, S-E.; Gong Y-D.; Macromol. Chem. Symp. 2002, 15, 565.

22. Lorthioir, O.; Carr R. A. E.; Congreve, M. S.; Geysen, M. H.; Kay, C.; Marshall, P.; McKeown S. C.; Parr, N. J.; Scicinski, J. J.; Watson S. P.; Anal. Chem. 2001, 73, 963.

23. Galindo, F.; Altava, B.; Burguete, M. I.; Gavara, R.; Luis, S. V.; J. Comb. Chem. 2004, 6, 859.

24. Shannon, S. K.; Barany, G.; J. Comb. Chem. 2004, 6, 165.

25. Gaggini, F.; Porcheddu, A.; Reginato, G.; Rodriquez, M.; Taddei, M.; J. Comb. Chem. 2004, 6, 805.
26. Cho, J. K.; White, P. D.; Klute, W.; Dean, T. W.; Bradley, M.; J. Comb. Chem. 2003, 5, 632.

27. Cournoyer, J. J.; Kshirsagar, T.; Fantauzzi, P. P.; Figliozzi, G. M.; Makdessian, T.; Yan, B.; J. Comb. Chem. 2002, 4, 120.

28. Amo, V.; Mc Glone, A. P.; Foster, C.; Anthony P. Davis, A. P.; J. Comb. Chem. 2005, 7, 1.

29. Shaughnessy, K. H.; Kim, P. H.; Hartwig, J. F.; J. Am. Chem. Soc. 1999, 121, 2123.

30. Walsh, D. P.; Pang, C.; Parikh, P. B.; Kim, Y. S.; Chang, Y. T.; J. Comb. Chem. 2002, 4, 204.

31. Yan, B.; Liu, U.; Astor, C. A.; Tang, Q.; Anal.Chem. 1999, 71, 4564.

32. Pina-Luis, G.; Badía, R.; Díaz-García, M. E.; Rivero, I. A.; J. Comb. Chem. 2004, 6, 391.

33. Merrifield, R. B.; J. Am. Chem. Soc. 1963, 85, 2149.

34. Obrecht, D.; Villalgordo, J. M.; Solid-Supported Combinatorial and Parallel Synthesis of Small Molecular-Weight Compound Libraries, Tetrahedron Organic Series, vol. 17, Pergamon Press: Oxford, 1998.

35. Harris, D. C.; Quantitative Chemical Analysis, 5 $^{\text {th }}$ ed.; W.H. Freeman and Company: New York, 1999.

36. Rueter, J. K.; Nortey, S. O.; Baxter, E. W.; Leo, G. C.; Reitz, A. B.; Tetrahedron Lett. 1998, 39, 975.

Submitted: April 12, 2010 Published online: February 10, 2011 